\title{
Adaptasi Test of Mathematical Ability (TOMA-3)
}

\author{
Nani Restati Siregar ${ }^{1^{*}}$, Supra Wimbarti ${ }^{2}$, Sri Kusrohmaniah ${ }^{3}$, Yulius \\ Sunardi ${ }^{4}$ \\ 1,2,3Universitas Gadjah Mada, Yogyakarta, Indonesia; ${ }^{1 *}$ nani.restati.s@mail.ugm.ac.id; \\ ²upra@ugm.ac.id; ${ }^{2}$ koes psi@ugm.ac.id \\ ${ }^{4}$ Universitas Sanata Dharma, Yogyakarta, Indonesia; nardiiranu@yahoo.com
}

Info Artikel: Dikirim: 12 Februari 2020 ; Direvisi: 21 Maret 2020; Diterima: 8 September 2020

Cara sitasi: Siregar, N. R., Wimbarti, S., Kusrohmaniah, S., \& Sunardi, Y. (2020). Adaptasi Test of Mathematical Ability (TOMA-3). JNPM (Jurnal Nasional Pendidikan Matematika), 4(2), 211-220

\begin{abstract}
Abstrak. Adaptasi tes kemampuan matematika untuk penelitian secara luas yang melibatkan berbagai lintas usia dan jenjang tingkat pendidikan formal belum banyak dilakukan. Tujuan penelitian ini agar menghasilkan tes test of mathematical ability (TOMA-3) versi Indonesia. Penelitian menggunakan metode survey dengan yang melibatkan penilaian ahli kepada 6 dosen dan 12 guru. Adapun proses adaptasi meliputi: penerjemahan bahasa, penilaian ahli terhadap konten sub tes soal cerita, uji keterbacaan oleh siswa sekolah dasar dan uji coba untuk memperoleh koefisien reliabilitas. Uji coba tes hasil adaptasi dilakukan kepada siswa sekolah dasar berjumlah 84 orang siswa. Hasil penelitian menunjukan beberapa istilah dalam butir soal cerita perlu disesuaikan dengan kondisi anak-anak di Indonesia. Adapun indeks validitas konten sebesar 0,85 dan koefisien reliabilitas menggunakan alpha Cronbach sebesar 0,758. Koefisien reliabilitas tes asli sebesar 0,87 dengan menggunakan jumlah subyek yang lebih banyak pada rentang usia dan pendidikan subjek bervariasi. Sehingga TOMA-3 versi Indonesia dapat direkomendasikan sebagai tes terstandar baik digunakan secara individual maupun kolektif.
\end{abstract}

Kata Kunci: Tes Kemampuan Matematika, Penilaian Ahli, Indeks Validitas Konten, Reliabilitas.

Abstract. Adaptation of mathematical ability tests for research purposes are involving level of ages and formal education have not been done much. The Adaptation research for mathematics ability tests was aim to have an Indonesian version test of the TOMA-3. The adaptation process was consist of: language translation, experts judgement for reviewing content of mathematical word problem, try out to elementary school students and analyze for internal consistency reliability. The research method was survey by giving assessment form to 3 lecturers and 6 teachers as experts judgement. Therefore, the test was tried out to students in elementary school consist of 84 children. The results of the study showed several terms in mathematical word problem necessary to be adjusted to the conditions of children in Indonesia. The content validity index is 0.85 and the reliability coefficient using Cronbach's alpha is 0.758 . It is still lower than the original test reliability 
coefficient of 0.87 . Implication of this finding were Indonesian version of TOMA-3 can be recommended as a standard test used both individually and collectively.

Keywords: Test of mathematical ability, expert judgement, content validity index, reliability.

\section{Pendahuluan}

Kemampuan matematika menjadi prediktor terhadap prestasi matematika yang akan dicapai oleh siswa (Nizoloman, 2013; Siegler, Duncan, Davis-Kean, Duckworth, Claessen, Engel, \& Chen 2012). Sebaliknya, siswa yang mengalami kendala atau kesulitan dalam belajar matematika menghasilkan prestasi matematika yang rendah (Geary, 2011; Yeh, Cheng, Chen, Liao, \& Chan, 2019). Siswa yang mengalami kesulitan belajar matematika tersebut perlu mendapatkan asesmen melalui tes kemampuan matematika terstandar sehingga intervensi yang diberikan sesuai kebutuhan siswa (Swanson, Moran, Lussier \& Fung, 2014; Swanson, Lussier, \& Orosco, 2013; Swanson, Moran, Bocian, Lussier, \& Zhang, 2012). Salah satu tujuan menggunakan tes kemampuan matematika terstandar adalah untuk kepentingan penelitian secara luas (Sevecke, 2014; Azwar, 2016). Disisi lain, tes standar memuat kurikulum umum yang dapat diterapkan pada lintas usia dan lintas kelas (Chia, 2014) pada jenjang sekolah dasar dan menengah yang menerapkan hal tersebut.

Sejauh ini belum ada tes terstandar yang dapat digunakan oleh para peneliti di Indonesia khususnya peneliti lintas disiplin, misalnya psikologi pendidikan untuk mengeksplore kemampuan matematika siswa pada lintas usia dan jenjang pendidikan sekolah. Riset terdahulu melaporkan bahwa terdapat pengaruh pengajaran metakognisi terhadap kemampuan pemecahan masalah matematika pada siswa sekolah dasar (Niam, 2016). Riset tersebut mengukur kemampuan pemecahan masalah matematika menggunakan tes yang dibuat berdasarkan kompetensi matematika dan jenjang kelas sekolah yang diperlukan saat itu. Namun, tes kemampuan matematika tersebut bukan sebagai tes terstandar sehingga penggunaannya terbatas pada karakteristik subjek dan kompetensi tertentu saja. Penggunaan tes atau pengukuran kemampuan matematika pada skala yang lebih luas, misalnya untuk tujuan riset pada lintas usia, jenjang kelas dan pendidikan yang bervariasi sehingga mencakup kurikulum matematika secara umum ini yang disebut dengan tes terstandar (Azwar, 2016). Test of mathematical ability (TOMA) adalah salah satu tes terstandar yang telah digunakan oleh para ahli bidang psikologi pendidikan dan ilmu pendidikan lainnya dalam penelitian baik untuk mengukur kemampuan matematika pada anak usia pra sekolah maupun usia sekolah dasar sampai dengan sekolah menengah (Brown, Cronin, \& Bryant, 
2013; Nuerk, Moeller, \& Willmes, 2015). Skor yang diperoleh individu adalah berdasarkan sejumlah jawaban benar selanjutnya dikonversikan dengan skor skala untuk menentukan kategori kemampuan matematika yang dicapai individu (Azwar, 2017). Oleh karena itu, untuk dapat menggunakan TOMA3 dari versi bahasa inggris ke bahasa Indonesia maka diperlukan prosedur adaptasi alat ukur. Tes TOMA-3 yang diadaptasi ke versi bahasa Indonesia adalah pada sub tes soal cerita. Salah satu prosedur adaptasi tes tersebut tidak memerlukan back translate karena yang terpenting adalah memahami apa konten tiap butir atau soal di alam tes, bukan menerjemahkan kata perkata (Bjork \& Bowyer-Crane, 2013). TOMA-3 merupakan edisi revisi yang diterbitkan oleh penerbit pro-ed di Amerika Serikat pada tahun 2013. Tes kemampuan matematika ini awalnya dengan sebutan TOMA (test of mathematical ability) selanjutnya dilakukan revisi di tahun 1994 menjadi TOMA-2. TOMA-2 juga memiliki sub-tes soal cerita yang dapat digunakan sebagaimana TOMA-3 (Griffin, 2019).

Tujuan penelitian ini adalah untuk melakukan adaptasi soal cerita yang merupakan sub tes dari test of mathematical ability (TOMA-3) melalui penilaian ahli (expert judgement). Soal cerita dalam matematika merepresentasikan pemecahan masalah (Johnson \& Clohessy, 2014) yang memerlukan berpikir tingkat tinggi atau higher order thinking skills (HOTS) (Roy \& Roth, 2016). Siswa perlu menguasai dua keterampilan sekaligus, yakni berhitung juga kemampuan pemahaman bacaan. Soal cerita memainkan peran penting di tingkat pendidikan dasar sebagai kemampuan dasar untuk memahami aljabar di jenjang sekolah menengah (Berkowitz \& Stern, 2018; Hsio, Lin, Chen, \& Peng, 2018). TOMA-3 terdiri dari beberapa sub-tes, diantaranya: konsep dan simbol dalam matematika, berhitung, matematika dalam kehidupan seharihari, soal cerita dan sikap pada matematika. Sub-tes konsep dan simbol dalam matematika dan sub-tes berhitung tidak memerlukan proses adaptasi yang rumit dikarenakan penggunaan simbol maupun angka dalam matematika adalah sama baik di Indonesia dan di Barat. Sub-tes soal cerita memerlukan proses penyesuaian relatif lebih kompleks. Hal dikarenakan tidak hanya menerjemahkan bahasa namun juga melakukan penyesuaian penggunaan istilah keseharian yang terdapat di Barat namun tidak ditemukan di Indonesia.

\section{Metode}

Penelitian ini menggunakan metode survey. Subyek dalam penelitian ini yaitu guru-guru sekolah dasar dan dosen pada program studi/jurusan pendidikan matematika serta siswa dari beberapa sekolah dasar negeri (SDN) di kota Yogyakarta. Guru sekolah dasar terdiri dari 12 orang untuk menilai 
kesesuaian kompetensi soal cerita pada TOMA-3 bagi siswa sekolah dasar di Indonesia. Dosen berlatar belakang pendidikan matematika berjumlah 2 orang yang fokus pada penilaian kurikulum matematika di sekolah dasar.

Penerjemah bahasa dalam hal ini melibatkan 2 orang dosen yang mana salah satu dosen bergelar magister bahasa inggris dari Amerika dan lainnya guru besar dalam bidang ilmu matematika. Hasil adaptasi diuji cobakan kepada siswa sekolah dasar yang berjumlah 84 orang siswa dengan rentang usia antara 9 sampai dengan 12 tahun. Adapun prosedur adaptasi alat ukur TOMA-3 adalah diuraikan pada Tabel 1.

Tabel 1. Proses Adaptasi Alat Ukur

\begin{tabular}{ll}
\hline Tahapan & Uraian \\
\hline Penterjemahan & $\begin{array}{l}\text { Terdiri dari } 2 \text { orang masing-masing menguasai bahasa inggris yang } \\
\text { mana } 1 \text { orang adalah berprofesi sebagai dosen bahasa inggris dan } \\
\text { lainnya menguasai ilmu matematika }\end{array}$ \\
Sintesis 1 & $\begin{array}{l}\text { dari kedua ahli hasil terjemahan tersebut kemudian dicari persamaan } \\
\text { dan perbedaannya, dan selanjutnya dibuat menjadi draft tes }\end{array}$ \\
$\begin{array}{l}\text { Penilaian ahli } \\
\text { (expert }\end{array}$ & $\begin{array}{l}\text { draft tes selanjutnya dinilai kelayakan konten oleh para guru SD dan } \\
\text { judgement) }\end{array}$ \\
$\begin{array}{ll}\text { Sintesis 2 } & \text { melaporkan dan mendisukusikan hasil penilaian ahli tersebut kepada } \\
\text { ahli pengukuran tes kognitif }\end{array}$ \\
$\begin{array}{l}\text { Uji } \\
\text { keterbacaan }\end{array}$ & $\begin{array}{l}\text { kepada } 2 \text { orang siswa SD. Hal ini bertujuan untuk mengetahui mana } \\
\text { kalimat yang membingungkan dan perlu disesuaikan. }\end{array}$ \\
$\begin{array}{l}\text { Uji coba (try } \\
\text { out) }\end{array}$ & $\begin{array}{l}\text { kepada siswa SDN sebanyak } 84 \text { orang yang berasal dari 3 SDN negeri } \\
\text { di kota Yogyakarta. }\end{array}$ \\
\hline
\end{tabular}

TOMA-3 tersebut pada sub tes soal cerita memiliki 30 jumlah butir soal. Butir soal tersebut dimulai dengan yang termudah sampai dengan tersulit. Para penilai ahli (expert judgement) memberikan evaluasi pada tiap-tiap aitem dengan memberikan tanda centang pada format pilihan sebagai berikut : (a) esensial; (b) berguna tapi tidak esensial; (c) tidak diperlukan. Penilaian para expert judgement tersebut dianalisis dengan menggunakan statistik content validity ratio (CVR) untuk melihat validitas isi butir atau soal. Selain validitas isi soal juga dilakukan analisis statistik content validity index (CVI) yang merupakan indikasi validitas isi tes (Azwar, 2016). 


\section{Hasil dan Pembahasan}

Adaptasi TOMA-3 secara umum terlaksana dengan baik sesuai dengan tahapan. Hasil terjemahan soal cerita oleh kedua penerjemah tidak ditemukan perbedaan yang ekstrim, hanya terdapat beberapa butir soal yang mana penerjemah satunya menerjemahkan dengan kalimat yang lebih panjang dimana penerjemah lainnya lebih singkat. Salah satu kalimat yang dimaksud, misalnya pada aitem "Emma uses stamping to make birthday cards for her friends. She has 7 sheets of paper. She can make two cards from each sheet of paper. How many cards can she make?". Hasil terjemahan kedua penerjemah tersebut selanjutnya peneliti melakukan sintesa dan menghasilkan kalimat menjadi "Emma menggunakan stempel untuk membuat kartu ulang tahun buat teman-temannya. Dia memiliki 7 lembar kertas dan setiap kertas dapat dibuat dua buah kartu. Berapa banyak kartu yang dihasilkan?". Kalimat awal hasil terjemahan yaitu "Emma menggunakan stempel untuk membuat kartu ulang tahun buat teman-temannya. Dia memiliki 7 lembar kertas. Dia dapat membuat dua buah kartu untuk setiap lembar kertasnya. Berapa banyak kartu yang ia bisa buat?".

Tes kemampuan matematika termasuk dalam kategori tes kognitif (Kyllonen \& Kell, 2018) berbeda dengan tes kepribadian yang lebih banyak mengandung unsur budaya setempat tes tersebut diciptakan. Oleh karenanya penerjemahan tes soal cerita dari sub test of mathematical ability (TOMA-3) tidak banyak mengalami kendala penerjemahan oleh kedua ahli sebelumnya. Disisi lain, isu mengenai penelusuran aspek kepribadian individu diintegrasikan dengan kemampuan kognitifnya (Nesayan, Amani, \& Gondomani, 2019) telah lama menjadi usulan para ahli. Aspek kognitif telah menjadi faktor yang diperhitungkan dalam memprediksi sosio-emosional individu, selain sebagai faktor utama dalam kesuksesan akademik (Phillipson \& Phillipson, 2012).

Tahap penilaian ahli (expert judgement) terhadap keseluruhan butir soal dalam tes yang berjumlah 30 soal menghasilkan indeks validitas konten atau content validity index (CVI) sebesar 0,85. Namun dari 30 soal tersebut, terdapat 1 soal yang memiliki nilai content validity ratio (CVR) sebesar -0,75. Ini mengindikasikan soal tersebut tidak memenuhi syarat validitas, disisi lain 29 soal lainnya memiliki nilai CVR di atas 0,5 yang mana artinya memenuhi syarat validitas isi. Aitem soal yang dimaksud berbunyi " A deck cards has 52 cards. There are four suits (spades, clubs, diamonds, and hearts). If a card is picked at random, what is the probability that card is a diamond?". Para expert judgement memberikan komentar yang sama bahwa soal tersebut belum diajarkan pada kurikulum siswa sekolah dasar. Namun keberadaan butir soal tersebut tetap digunakan dalam penelitian ini karena tidak dibenarkan untuk dihilangkan atau aitem tersebut diganti dengan butir soal lain. Indeks validitas konten atau 
content validity index (CVI) adalah studi penting dalam desain maupun adaptasi alat ukur (Zamanzadeh, Ghahramanian, Rassouli, Abbaszadeh, Alavi-Majd, \& Nikanfar, 2015). CVI dihasilkan melalui skor total dari tiap aitem dalam suatu alat ukur. Disisi lain, content validity ratio (CVR) merupakan nilai yang diperoleh tiap aitem atau soal berdasarkan penilaian oleh sekelompok expert judgement. Nilai CVR yang sangat rendah ditemukan hanya satu aitem dari soal cerita TOMA-3 seperti yang telah disebutkan sebelumnya.

Hasil terjemahan TOMA-3 dan evaluasi oleh expert judgement selanjutnya diberikan kepada dua orang siswa sekolah dasar yang diambil secara acak (dengan syarat dapat membaca dan berhitung). Tujuan uji keterbacaan ini adalah untuk mengetahui apakah bahasa yang terdapat dalam butir soal tes TOMA-3 dapat dipahami oleh siswa sekolah dasar pada umumnya yang akan menjadi subyek penelitian dan tentunya memiliki karakteristik yang sama dengan subyek uji keterbacaan. Uji keterbacaan ini diperlukan sebelum melakukan uji coba tes dalam jumlah subyek yang besar termasuk tujuannya untuk menyesuaikan dengan istilah-istilah yang umumnya dikenal oleh anakanak di Indonesia (Ercikan \& lyons-Thomas, 2013)

Hasil analisis reliabilitas tes kemampuan matematika (TOMA-3) dengan sub tes soal cerita menggunakan alpha Cronbach menghasilkan nilai $r 0,758$. Nilai reliabilitas sub tes soal cerita yang diperoleh sebelumnya sebesar $r 0,87$. Ini menunjukan terdapat perbedaan antara nilai reliabilitas tes asli yang masih versi bahasa inggris dengan nilai koefisien reliabilitas hasil adaptasi. Ini dikarenakan tes asli versi bahasa inggris tersebut menggunakan subyek dengan lintas usia dengan kelompok berkesulitan $(n=60)$ dan tanpa berkesulitan matematika $(n=1.396)$ yang bervariasi mulai dari siswa sekolah dasar sampai dengan sekolah menengah (Brown, Cronin, \& Bryant, 2013). Adapun hasil adaptasi tes soal cerita kali ini hanya menggunakan subyek siswa sekolah dasar kelas tinggi, yakni mulai kelas 4, 5 dan 6 . Perbedaan dan keterbatasan keberagaman subyek (Stewart, Thrasher, Goldberg, \& Shen, 2012) dari aspek usia dan jenjang pendidikan (Ursachi, Horodonic, \& Zait, 2015) memungkinkan nilai reliabilitas lebih rendah dari nilai reliabilitas tes aslinya. TOMA-3 yang telah melewati proses adaptasi ke dalam versi bahasa Indonesia diharapkan dapat menjadi alat ukur di dunia pendidikan baik untuk tujuan riset dengan jumah subjek besar maupun untuk keperluan asesmen di sekolah khususnya pada siswa yang diduga mengalami kendala pada pelajaran matematika sehingga dapat menentukan jenis intervensi yang diberikan. 
TOMA-3 telah digunakan oleh para peneliti sebelumnya untuk mengukur kemampuan pemecahan masalah matematika baik bagi anak-anak yang mengalami gangguan dalam perkembangan maupun yang berkembang secara normal (Bae, Chiang, \& Hickson, 2015; Swanson, Lussier, \& Orosco, 2015). Temuan para ahli menunjukan bahwa anak-anak yang berkembang secara normal lebih mampu memecahkan masalah matematika dibandingkan anak-anak yang mengalami gangguan dalam perkembangan. Kemampuan pemecahan soal cerita matematika seperti halnya dengan pemahaman membaca yang didukung oleh kapasitas kognitif, misalnya ingatan kerja (Siregar, Ilham, \& Mansyur, 2020) melibatkan beberapa faktor lain yang menguatkan kemampuan pemecahan masalah tersebut. Faktor sikap terhadap matematika (Siregar, Wimbarti, \& Ilham, 2019), membaca, berhitung dan kecerdasan fluid mendasari kemampuan pemecahan soal cerita matematika yang diukur dengan menggunakan TOMA-3 (Fung \& Swanson, 2017).

Riset adaptasi TOMA-3 versi Indonesia masih memiliki kekurangan, yakni penggunaan subjek penelitian yang terbatas pada siswa sekolah dasar di Kota Yogyakarta. Studi berikutnya menggunakan ukuran sampel penelitian yang lebih banyak dan bervariasi dalam jenjang sekolah serta melibatkan adaptasi sub-tes penggunaan matematika dalam kehidupan sehari-hari sebagaimana sub-tes soal cerita yang merepresentasikan kemampuan pemecahan masalah.

\section{Simpulan}

Adaptasi tes kemampuan matematika atau test of mathematical ability (TOMA3) bagi siswa sekolah dasar di Indonesia (diwakili oleh 3 sekolah dasar di kota Yogyakarta) menghasilkan beberapa perubahan tertentu, misalnya nama acara televisi disesuaikan dengan yang familiar bagi anak-anak di Indonesia. Nilai konsistensi internal yang dihasilkan melalui uji coba tes matematika tersebut dengan menggunakan alpha Cronbach menghasilkan koefisien yang lebih rendah dibanding konsitensi internal tes asli. Hal ini disebabkan karena hanya melibatkan subjek siswa sekolah dasar saja. Tes soal cerita TOMA-3 versi Indonesia dapat digunakan baik untuk keperluan penelitian dan sebagai asesmen untuk keperluan intervensi bagi siswa sekolah dasar yang diduga mengalami kesulitan belajar pemecahan soal cerita baik secara individual maupun kolektif.

\section{Daftar Pustaka}

Azwar, S. (2016). Konstruksi Tes Kemampuan Kognitif. Yogyakarta: Pustaka Pelajar. Azwar, S. (2017). Metode Penelitian Psikologi. Yogyakarta: Pustaka Pelajar. 
Bae, Y. S., Chiang, H. M., \& Hickson, L. (2015). Mathematical Word Problem Solving Ability of Children with Autism Spectrum Disorder and Their Typically Developing Peers. J Autism Dev Disord. 45(7), 2200-2208.

Berkowitz, M., \& Stern, E. (2018). Which Cognitive Abilities Make the Difference? Predicting Academic Achievements in Advanced STEM Studies. Journal of Intelligence 6(4), 48-58.

Bjork, I., \& Bowyer-Crane, C. (2013). Cognitive Skills Used to Solve Mathematical Word Problems and Numerical Operations: A Study of 6- to 7-year-old Children. European Journal of Psychology of Education 28(4), 1345-1360.

Brown, V. L., Cronin, M. E., \& Bryant, D. P. (2013). Test of Mathematical Ability (TOMA-3) Examiner Manual $3^{\text {rd }}$ ed. Texas: Pro-ed an Publisher.

Chia, N. K. H. (2014). A Comparison of Cognitive Equations of Mathematics Learning Process Between the American and Singaporean Students With Dyscalculia. Educational Research International, 3(1), 1-14.

Ercikan, K., \& Lyons-Thomas, J. (2013). Adapting Tests for Use in Other Languages And Cultures. In K. F. Geisinger, B. A. Bracken, J. F. Carlson, J.-I. C. Hansen, N. R. Kuncel, S. P. Reise, \& M. C. Rodriguez (Eds.). APA handbook of testing and assessment in psychology. Testing and assessment in school psychology and education (pp. 545-569). American Psychological Association.

Fung, W. \& Swanson, H.L. (2017). Working Memory Components that Predict Word Problem Solving: Is It Merely a Function of Reading, Calculation, and Fluid Intelligence? Memory \& Cognition 45 (5), 804-823.

Geary D. C. (2011). Consequences, Characteristics, and Causes of Mathematical Learning Disabilities and Persistent Low Achievement in Mathematics. Journal of Developmental and Behavioral Pediatrics: JDBP 32(3), 250-263.

Griffin, H. C. (2019). Review of the Test of Mathematical Abilities-2 (TOMA-2). Measurement and Evaluation in Counseling and Development 29(4), 242-244.

Hsiao, H., Lin, C., Chen, J., \& Peng, Y. (2018). The Influence of a Mathematics Problem-Solving Training System on First-Year Middle School Students. Eurasia Journal of Mathematics, Science and Technology Education 14(1), 77-93.

Johnson, E. S., \& Clohessy, A. B. (2014). Identification and Evaluation of Learning Disabilities. The School Team's Guide to Students Succes. California: Corwin.

Kyllonen, P. C., \& Kell, H. (2018). Ability Tests Measure Personality, Personality Tests Measure Ability: Disentangling Construct and Method in Evaluating the Relationship between Personality and Ability. Journal of Intelligence 6(3), 32-42.

Nesayan, A., Amani, M., \& Gandomani, R. A. (2019). Cognitive Profile of Children and its Relationship with Academic Performance. Basic and Clinical Neuroscience 10(2), 165-174.

Niam, M. M. (2016). Pengaruh Strategi Metakognitif terhadap Kemampuan Pemecahan Masalah Matematika dan Perubahan Gelombang Otak. Tesis. Yogyakarta: Universitas Gadjah Mada.

Nizoloman, A. N. (2013). Relationship between Mathematical Ability and Achievement in Mathematics among Female Secondary School Students in Bayelsa State Nigeri. Procedia - Social and Behavioral Sciences 106, 2230-2240.

Nuerk, H.-C., Moeller, K., \& Willmes, K. (2015). Multi-Digit Number Processing: Overview, Conceptual Clarifications, and Language Influences. In R. C. Kadosh \& A. Dowker (Eds.). Oxford library of psychology. The Oxford handbook of numerical cognition (p.106139). Oxford: University Press.

Phillipson, S., \& Phillipson, S. N. (2012). Children's Cognitive Ability and Their Academic Achievement: The Mediation Effects of Parental Expectations. Asia Pacific Educ. Rev. 13, 495-508. 
Roy, S. \& Roth, D. (2016). Solving General Arithmetic Word Problems. Proceedings of Conference on Empirical Methods in Natural Language Processing 1743-1752.

Sevecke, J. R. (2014). Test Review: Test of Mathematical Abilities. Journal of Psychoeducational Assesment 32(6), 581-584.

Siegler, R. S., Duncan, G. J., Davis-Kean, P. E., Duckworth, K., Claessen, A., Engel, M. ..\& Chen, M. (2012). Early Predictors of High School Mathematics Achievement. Psychological Science 23(7), 691-697.

Siregar, N. R., Ilham, M., \& Mansyur, M. (2020). The Influence of Survey, Question, Read, Recite, Review Method Toward Reading Comprehension Ability Mediated by Working Memory. Jurnal Pendidikan Indonesia 9(1), 85-94.

Siregar, N. R., Wimbarti, S., \& Ilham, M. (2019). Individual Differences in Attitudes Toward Mathematics. Journal of Physics: Conference Series 1188(1), 1-10.

Stewart, A. L., Thrasher, A. D., Goldberg, J., \& Shen, J. (2012). A Framework for Understanding Modifications to Measure for Diverse Populations. J Aging Health 24(6), 992-1017.

Swanson, H. L., Lussier, C. M., \& Orosco, M. J. (2015). Cognitive Strategies, Working Memory, and Growth in Word Problem Solving in Children with Math Difficulties. Journal of Learning Disabilities 48(4), 339-358.

Swanson, H. L., Moran, A., Lussier, C. B., \& Fung, W. (2014). The Effect of Explicit and Direct Generative Strategy Training and Working Memory on Word Problem-Solving Accuracy in Children at Risk for Math Difficulties. Learning Disability Quarterly 37(2), 111-123.

Swanson, H. L., Lussier, C., \& Orosco, M. (2013). Effect of Cognitive Strategy Intervention and Cognitive Moderators on Word Problem Solving in Children at Risk for Problem Solving Difficulties. Learning Disabilities Research E Practice 28(4), 170-183.

Swanson, H. L., Moran., A. S., Bocian., K., Lussier, C., \& Zheng, X. (2012) Generative Strategies, Working Memory and Word Problem Solving Accuracy in Children at Risk for Math Disabilities. Learning Disabilities Quarterly 36(4), 202-214.

Ursachi, G., Horodnic, I. A., \& Zait, A. (2015). How Reliable Measurement Scales? External Factors with Indirect Influence on Reliability Estimators. Procedia Economics and Finance 20, 679-689.

Yeh, C. Y. C., Cheng, H. N. H., Chen, Z., Liao, C. C. Y., \& Chan, T. W. (2019). Enhancing Achievement and Interest in Mathematics Learning Through Math-Island. RPTE 14(5), $1-10$.

Zamanzadeh, V., Ghahramanian, A., Rassouli, M., Abbaszadeh, A., Alavi-Majd, H., \& Nikanfar, A. R. (2015). Design and Implementation Content Validity Study: Development of an Instrument for Measuring Patient-Centered Communication. Journal of Caring Sciences 4(2), 165-178. 